\title{
Transoral Robotic Resection of Lingual Thyroid
}

\author{
Kalpana Nagpal*, Noor Ul Din Malik, Shaili Priyamvada, and Kamal Goyal \\ Department of ENT, Indraprastha Apollo Hospital, India
}

*Corresponding author: Kalpana Nagpal, Department of ENT, Head \& Neck Surgery and Robotic Surgery, Indraprastha Apollo Hospital, Sarita Vihar, New Delhi, India

Abbreviations: TORS: Transoral Robotic surgery; TSH: Thyroid Stimulating Hormone; US: Ultra Sonography

\section{Introduction}

Surgical removal of ectopic lingual thyroid is indicated in symptomatic patients or in cases of suspected malignancies. An external approach is most often used but is associated with morbidity and visible scar on cervical region. In this case we utilized Transoral Robotic surgery [TORS] to excise ectopic lingual thyroid tissue. Ectopic thyroid refers to the presence of thyroid tissue in locations other than the normal anterior neck region between the second and fourth tracheal cartilages. It is the most frequent form of thyroid dysgenesis, accounting for $48-61 \%$ of the cases [1]. Lingual thyroid is a rare developmental anomaly originating from aberrant embryogenesis during the passage of the thyroid gland through the neck. Prevalence of this condition is reported to be between 1 per 100,000-300,000 persons and occur one in 4,0008,000 patients with thyroid disease [2]. To date, about 500 cases have been reported in the English literature mainly from Europe, Asia and America, with a small number of reports coming from Africa. Sixty-five to eighty percent of cases occurred in females [2]. Although it is difficult to detect asymptomatic thyroid ectopy, postmortem studies have suggested that $7-10 \%$ of adults may harbor asymptomatic thyroid tissue along the path of the thyroglossal duct [3]. In 1869, Hickman reported the first case of ectopic thyroid tumour of the base of the tongue, pressing down the epiglottis on the larynx and causing death by suffocation sixteen hours after birth [4]. In 1999, da-Vinci robot was developed by intuitive company in USA. It contains high magnification 3-D endoscope, endo-wristed instruments with motion scaling and tremor filtration function that help surgeons to perform endoscopic surgery with more precision, dexterity and control. conventional transoral approach has the disadvantages of limited exposure and difficulty in manipulation and hemostasis [5]. In this paper we report a case of 16 years old lady from Nepal who presented to our hospital with choking symptoms which are more during night since years. She was treated as an asthmatic and had no improvement with bronchodilators. She was referred to our center for further evaluation to rule out any ENT cause. Fiberoptic laryngoscopy lead to provisional diagnosis of lingual thyroid. She underwent excision of ectopic thyroid tissue by Da Vinci robotic surgical system. Histopathological examination confirmed lingual thyroid (Figure 1).

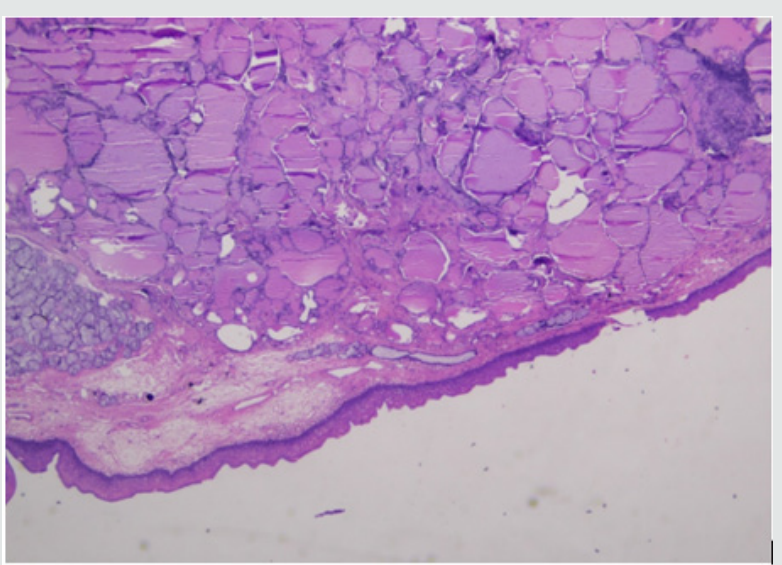

Figure 1: Photomicrograph of histology section, Hematoxylin Eosin stain, $10 \times$ magnification, showing covering of normal squamous epithelium of tongue, with many variable sized colloids filled thyroid follicles in the subepethelium.

\section{Case Report}

A 16-year-old female presented with dyspnoea especially at night and foreign body sensation throat. The patient also had 
complaints of dysphagia. She had no history of either past or present thyroid disease. Upon examination, the patient presented a solid, pink, spherical mass, covered with intact mucosa, located at the base of the tongue. Examination of the neck revealed no palpable thyroid gland in the normal pre-tracheal position and no cervical adenopathy. Thyroid hormone tests showed normal thyroid-stimulating hormone (TSH) concentrations and normal FT3 and FT4 concentrations. Patient was clinically euthyroid. Ultrasonography (US) revealed a mass $5 \mathrm{x} 4 \mathrm{~cm}$ in size with distinct margins restricted to the base of the tongue and absence of the thyroid gland. A thyroid scan with technetium Tc-99m sodium was performed showing marked isotope uptake in the area of the tongue and no uptake in the neck (Figure 2).

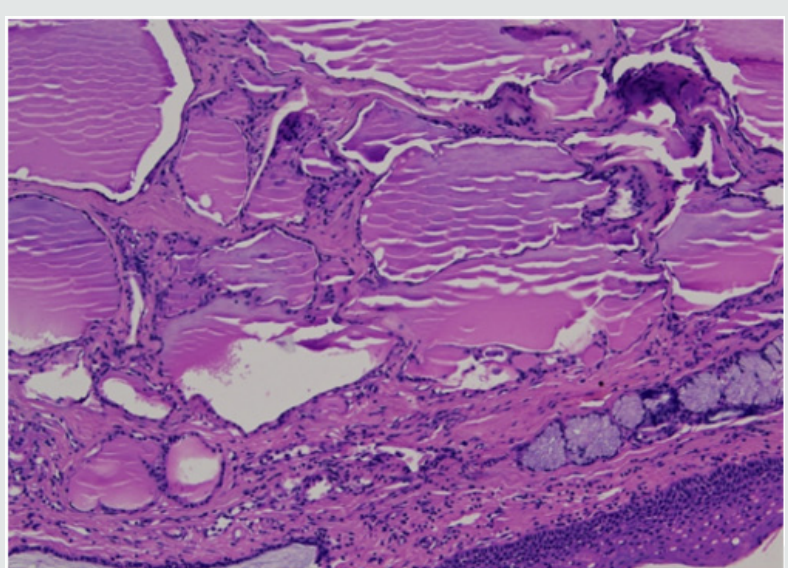

Figure 2: Photomicrograph of histology section, $\mathrm{H}$ \& $\mathrm{E}$ stain, 20 X, with similar features as in slide 1.

\section{Method}

Patient was taken up for transoral robotic surgical excision of lingual thyroid tissue under

general anesthesia. The da Vinci Si surgical system (Intuitive Surgical, Sunnyvale, CA) used.

a) Patient position is like Rose's position of tonsillectomy. Neck is extended by sandbag under the shoulders and the head is supported on a ring.

b) Painting \& draping done.

c) Docking of the robot done. Mass base of tongue visualized using 30 degree up endoscope. $4 \mathrm{~mm}$ instruments used for dissection.

d) Maryland dissector at left hand side and spatula tip electro-cautery at right hand side.

e) Resection carried out from the anterior border of the lingual thyroid along the capsule

f) of ectopic thyroid tissue. Mass excised in toto. Hemostasis confirmed. g) Undocking of robot done. GA withdrawn.

h) Excised tissue sent for histopathological examination.

i) Pt. kept in hospital overnight for observation. No postoperative complications.

j) Post operatively substitutive thyroid hormone replacement therapy was given.

Gross description: Multiple mucosa covered tissue pieces altogether measure $5 \times 2 \times 0.5 \mathrm{~cm}$. No ulcer or mass lesion is identified on the surface. The cut surface shows a brownish, colloid like appearance.

Microscopic description: Sections show unremarkable stratified squamous epithelial lining. The subepithelial stroma shows islands of normal thyroid follicles and few seromucinous salivary glands, with mild lymphoid cell infiltrate. There is no evidence of malignancy (Figure 3).

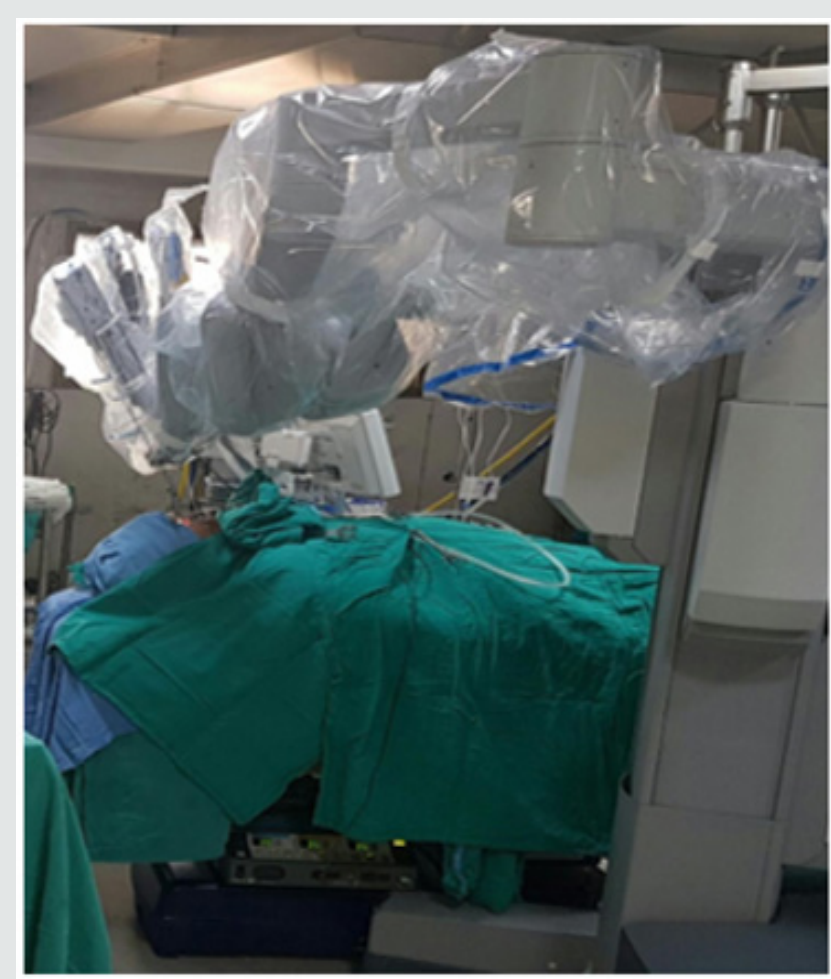

Figure 3: Docking of the robot for transoral surgery.

Conclusion: Excised swelling base of tongue - LINGUAL THYROID.

\section{Results}

TORS of ectopic lingual thyroid tissue was successfully performed with excellent functional outcomes and with decreased operating time than conventional tongue base surgeries. Less than $5 \mathrm{ml}$ blood loss during surgery and stay in the hospital was less than 24 hours (Figure 4). 


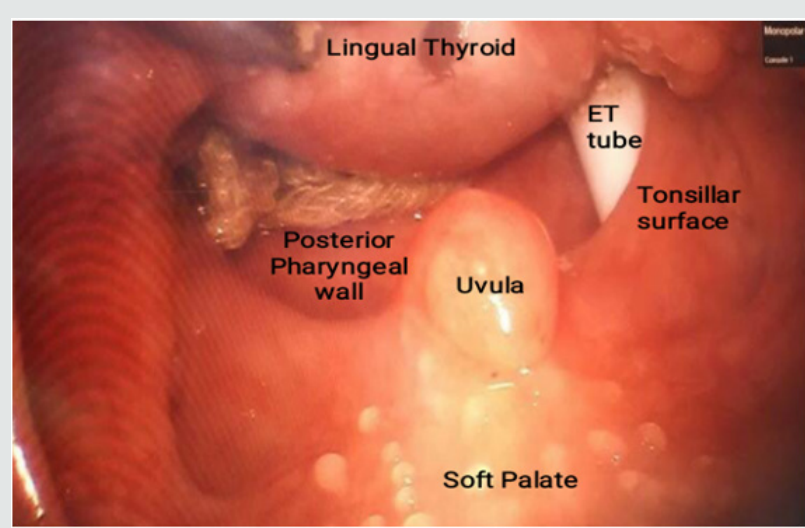

Figure 4: Intraoperative picture of mass.

\section{Discussion}

Lingual thyroid is reported to be a rare congenital anomaly in the population. Asymptomatic ectopic thyroid tissue becomes symptomatic in periods of puberty, pregnancy, menopause, inflammation, and stress. Thyroid requirement increasing in these periods leads TSH level to increase and hypertrophy in the thyroid gland [8]. Approach to lingual thyroid tissue may vary according to clinical findings, but it is still debatable. Although asymptomatic cases can be followed without management for probable complications, in symptomatic cases, there are alternative treatment methods. Even though thyroid suppressive treatment conducted with the administration of exogenous thyroid hormone is a method that can be preferred in patients with minimal symptoms, it is not preferred in that it requires long term treatment. Radioactive iodine treatment and surgery are other treatment alternatives. As it is in a region difficult to access, open surgical approaches have been used in surgical treatment [9]. These surgical approaches may lead morbidity rates to increase according to the method used since they require lip, tongue, and mandibular splitting or lateral, suprahyoid pharyngotomy and long operation times and feeding with nasogastric tube, they run the risk of the development of suprahyoid pharyngotomy, hospitalization is prolonged, and there are skin scars. In order to avoid these morbidities, transoral resection techniques including Co2 laser, electrocautery, and harmonic technologies are used.

Terris et al. [10] reported that transoral minimal invasive lingual thyroid resection decreased morbidity and duration of hospitalization compared to other open approaches. Coblation assisted lingual thyroid and lingual tonsil resection techniques were used and successful results were reported [11-13]. Leitzbach et al. [12] reported successful results and low complication rates in 108 patients undergoing coblation assisted resection due to tongue root and lingual tonsil hypertrophy. However, transoral resection techniques have limited point of view and lead to difficulty in resection owing to difficulty in manipulation, which restricts their use [6]. Studies have demonstrated that as the size of the mass increases, transoral respectability of the mass decreases. The basic principles of avoiding complications in transoral tongue root resections are careful dissection in accordance with imaging methods and adequate anatomic evaluation in order to prevent lingual artery injury [14]. Transoral robotic surgery decreases the technical difficulties encountered in other transoral approaches in that it has a three-dimensional larger point of view, and manipulation is easier thanks to robotic instruments, leading to its larger use in oropharyngeal and tongue root operations [7]. Transoral robotic surgery is used in many different regions in surgical otolaryngology $[15,16]$. Three robotic arms, 0 -degree and 30-degree high definition and 3-dimensional video instruments make it possible to overcome restriction of visualization of regions with difficult access and difficulty of manipulation. Lingual thyroid excision using this method has been described in previous studies $[17,18]$. The absolute local contraindication is related to the difficult exposition of the oropharynx, due to a limited opening of the mouth or the patient's habitus. TORS for treatment of ectopic lingual goiter is feasible, requires a short learning curve, and appears to be safe [19]. In addition, the robotic surgery also has been adopted to do esthetic neck surgery with better cosmetic outcomes by hiding the scar [20].

\section{Conclusion}

TORS assisted excision of ectopic lingual thyroid is minimally invasive, feasible method. It is a safe technique with minimum morbidity and decreased operative time. In experienced hands it should be offered as valid treatment for this pathology. Studies with larger case series and longer duration of follow-up are required in order to reach a definitive conclusion on this issue.

\section{References}

1. Felice Md, Lauro Rd (2004) Thyroid Development and Its Disorders: Genetic and Molecular Mechanisms. Endocrine Reviews 25(5): 722-746.

2. Yoon JS, Won KC, Cho iH, Lee Jt, Lee HW (2007) Clinical Characteristics of Ectopic Thyroid in Korea. Thyroid 17(11): 1117-1121.

3. Sauk JJ (1970) Ectopic Lingual Thyroid. J Pathology 102(4): 239-245.

4. Hickman W (1869) Congenital Tumor of the Base of the Tongue, Pressing Down the Epiglottis on the Larynx and Causing Death by Suffocation Sixteen Hours after Birth. Trans Pathol Soc Lond 20: 160-161

5. Man Wei Hua, Wen-Chun Lin, Chen-Chi Wang (2019) Triple Ectopic Thyroid Excision by Robotic Surgery via Trans-Oral and Post-Auricular Approach Report of a Case. Annals of Clinical Case Report 4: 1-4.

6. Dziegielewski PT, Chau JKM, Seikaly H, Allegretto M, Barber B, et al. (2011) Lingual Thyroid in Adults: Management Algorithm Based on Swallowing Outcomes. Journal of Otolaryngology-Head and Neck Surgery 40(1): 19-26.

7. O'Malley BW, Weinstein GS, Snyder W, Hockstein N (2006) Transoral Robotic Surgery (TORS) for Base of Tongue Neoplasms. The Laryngoscope 116(8): 1465-1472.

8. Thomas G, Hoilat R, Daniels JS, Kalagie W (2003) Ectopic Lingual Thyroid: A Case Report. International Journal of Oral \& Maxillofacial Surgery 32(2): 219-221. 
9. Atiyeh BS, Abdelnour A, Haddad FF, Ahmad H (1995) Lingual Thyroid: Tongue-Splitting Incision for Transoral Excision. The Journal of Laryngology and Otology 109(6): 520-524.

10. Terris DJ, Seybt MW, Vaughters RB (2010) A New Minimally Invasive Lingual Thyroidectomy Techniqu. Thyroid 20(12): 1367-1369.

11. Bock JM, Trask DK (2008) Coblation Assisted Lingual Tonsillectomy for Dysphagia Secondary to Tongue Base Hypertrophy. Annals of Otology, Rhinology and Laryngology 117(7): 506-509.

12. Leitzbach SU, Bodlaj R, Maurer JT, Hörmann K, Stuck BA (2014) Safety of Cold Ablation (coblation) in the Treatment of Tonsillar Hypertrophy of the Tongue Base. European Archives of Oto-Rhino-Laryngology 271(6): 1635-1639.

13. Rabiei S, Rahimi M, Ebrahimi A (2010) Coblation Assisted Excision of Lingual Thyroid. Indian Journal of Otolaryngology and Head \& Neck Surgery 62(2): 108-110.

14. Elif Ersoy CallJoglu, KazJm Bozdemir, Bulent Ulusoy, Tolga Oguzhan M (2015) Case Report Lingual Thyroid Excision with Transoral Robotic Surgery. Hindawi Publishing Corporation Case Reports in Otolaryngology 2015: p.4.
15. Lin HS, Rowley JA, Folbe AJ, Yoo GH, Badr MS, et al. (2015) Transoral Robotic Surgery for Treatment of Obstructive Sleep Apnea: Factors Predicting Surgical Response. The Laryngoscope 125(4): 1013-1020.

16. Ansarin M, Tagliabue M, Chu F, Zorzi S, Proh M, et al. (2014) Transoral Robotic Surgery in Retro styloid Parapharyngeal Space Schwannomas. Case Reports in Otolaryngology.

17. Teo EH, Toh ST, Tay HN, Han HJ (2013) Transoral Robotic Resection of Lingual Thyroid: Case Report. The Journal of Laryngology \& Otology 127(10): 1034-1037.

18. Howard BE, Moore EJ, Hinni ML (2014) Lingual Thyroidectomy: The Mayo Clinic Experience with Transoral Laser Microsurgery and Transoral Robotic Surgery. Annals of Otology, Rhinology \& Laryngology 123(3): 183-187.

19. Pellini R, Mercante G, Ruscito P, Cristalli G, Spriano G (2013) Ectopic Lingual Goiter Treated by Transoral Robotic Surgery. Acta Otorhinolaryngological Italica 33(5): 343-346.

20. Ji YB, Song CM, Bang HS, Park HJ, Lee JY, et al. (2017) Functional and Cosmetic Outcomes of Robot-Assisted Neck Dissection by a Postauricular Facelift Approach for Head and Neck Cancer. Oral Oncol 70: 51-57.

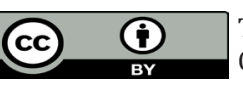

This work is licensed under Creative Commons Attribution 4.0 License

To Submit Your Article Click Here: Submit Article

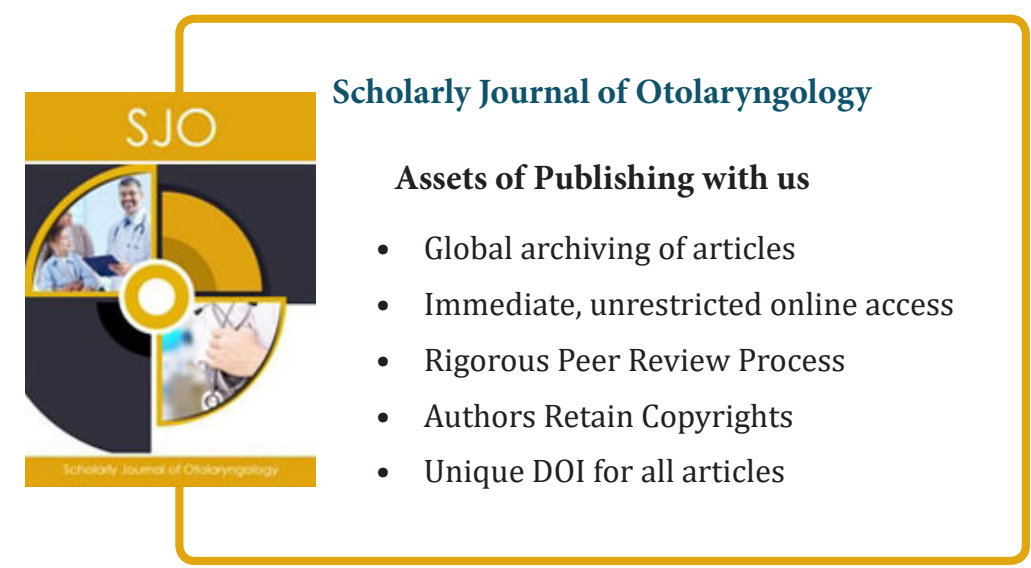

